\title{
ESTUDO DA EFICIÊNCIA DE COLETA DE PARTÍCULAS DE UM CICLONE ADAPTADO COM BICOS INJETORES DE ÁGUA
}

\author{
L. P. BORGES ${ }^{1}$, A. C. M. ALVES ${ }^{1}$ e V. G. G. BÉTTEGA ${ }^{1}$ \\ ${ }^{1}$ Universidade Federal de São Carlos, Departamento de Engenharia Química \\ E-mail para contato: borgeslaira@ @otmail.com
}

\begin{abstract}
RESUMO - Atualmente o Brasil é um dos maiores produtores de cana-de-açúcar e etanol no mundo. Junto com os principais produtos, temos o subproduto bagaço, que é utilizado na cogeração de energia, por meio da sua queima em caldeiras. Essa queima gera resíduos, em sua maioria fuligem, a qual é um material particulado com diâmetros médios menores que $10 \mu \mathrm{m}$, altamente nocivo ao meio ambiente e à saúde. Dessa forma é necessário o controle da emissão desse material, e dentre os equipamentos utilizados para isso está o separador ciclônico, que utiliza a força centrífuga para retirar o material particulado do ar. O objeto de estudo foi um separador ciclônico do tipo Stairmand modificado com a inclusão de bicos injetores de água. $\mathrm{O}$ intuito do estudo foi testar a eficiência de um ciclone associando sua força centrífuga à injeção de líquido para limpeza de uma corrente de ar contendo micropartículas, e compará-la à eficiência de ciclones secos. A eficiência de coleta do equipamento aumentou com a injeção de líquido, conforme esperado, assim como o aumento da eficiência com o aumento da vazão de água. Pequenas variações de eficiência também foram observadas entre cada configuração de bicos de injeção de líquido. Assim, os resultados obtidos validam a utilização de água para aumento da eficiência de um separador ciclônico.
\end{abstract}

\section{INTRODUÇÃO}

Separadores ciclônicos são equipamentos amplamente utilizados na indústria devido à algumas vantagens, como facilidade de construção, pouco espaço para instalação, baixo custo de operação (Chiabai Junior, 2014) e boa eficiência na coleta de materiais particulados com diâmetro em torno de $15 \mu \mathrm{m}$ (Lora, 2002). Eles combinam forças de arraste, peso, centrífuga e inércia para separar as partículas sólidas da corrente gasosa.

A proposta do ciclone úmido é unir a propriedade de separação do ciclone seco com mecanismos de assentamento de partículas nas gotas de líquido, por fatores de inércia, interceptação e difusão (Chiabai Junior, 2014). O líquido injetado no ciclone proporcionaria uma maior aglomeração das partículas, resultando numa coleta maior e consequentemente, aumento da eficiência do equipamento. Segundo Majewski (2006), é possível obter eficiências maiores que $90 \%$ quando aplicado na limpeza de partículas menor que $10 \mu \mathrm{m}$.

E entrada do fluido de limpeza ocorre transversalmente ao fluxo de gás e de forma tangencial à parede do lavador. A força centrífuga atua sobre os três componentes: gás, 
partículas e água, realizando a separação. A saída do gás limpo ocorre por cima, enquanto que o líquido com o material particulado é colhido embaixo, como é possível observar na Figura 1 .

Figura 1 - Representação do ciclone úmido.

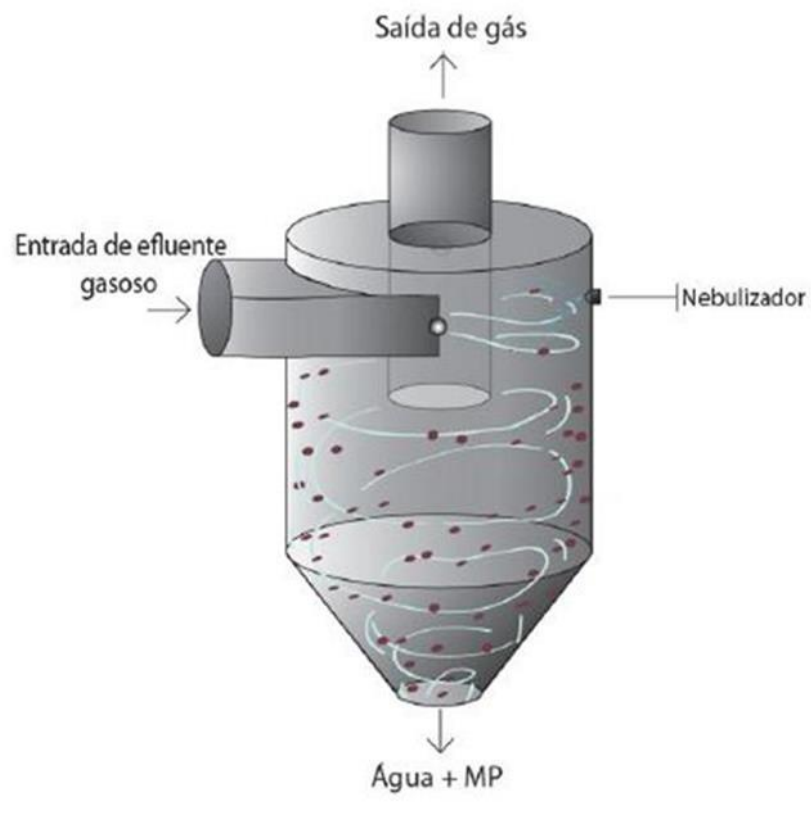

Logo, o objetivo desse estudo foi avaliar o desempenho de um ciclone adaptado com 8 bicos injetores de água na coleta de material particulado na faixa respirável, com variações na vazão de líquido, número e posição dos bocais de injeção de líquido.

\section{MATERIAIS E MÉTODOS}

\subsection{Aparato experimental}

O ciclone utilizado no projeto é um ciclone do tipo Stairmand com oito bicos injetores de líquido, sendo quatro bicos posicionados na parte superior do equipamento e outros quatro bicos na lateral. As dimensões do ciclone podem ser observadas na Figura 2.

O aparato experimental utilizado junto com o ciclone é apresentado na Figura 3. Uma corrente de ar foi alimentada na linha por um soprador (1), com o ajuste de velocidades realizado por válvulas (2), sendo uma válvula acoplada ao duto principal (3) e outra utilizada como purga. O gás passava pela seção retangular (4) e seguia para o duto de entrada (5).

No duto de entrada ocorria a alimentação de pó, por meio de um prato giratório (6). A rotação do prato era controlada por um variador de velocidades e o arraste de pó para o duto principal ocorria devido ao escoamento de ar comprimido (7).

$\mathrm{O}$ ar e o material particulado seguiam para o ciclone (8). O material particulado era retirado na caixa coletora (9), enquanto que o gás limpo sai pelo duto superior (10), detalhados na Figura 2 (b). 
Figura 2 - Vista geral do ciclone utilizado (a) Dimensões do ciclone (b) Detalhes da saída do ar no ciclone e caixa coletora.
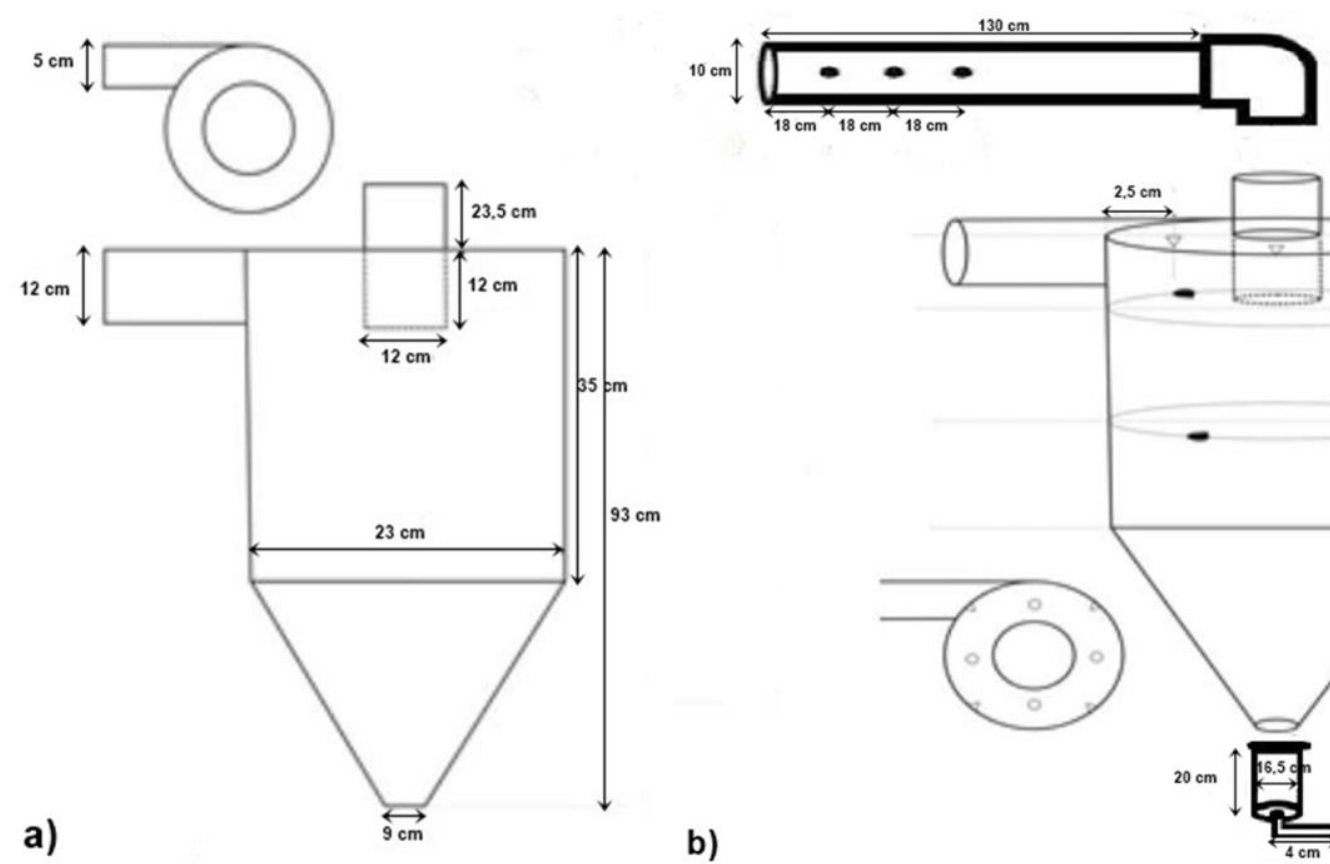

Figura 3 - Aparato experimental completo

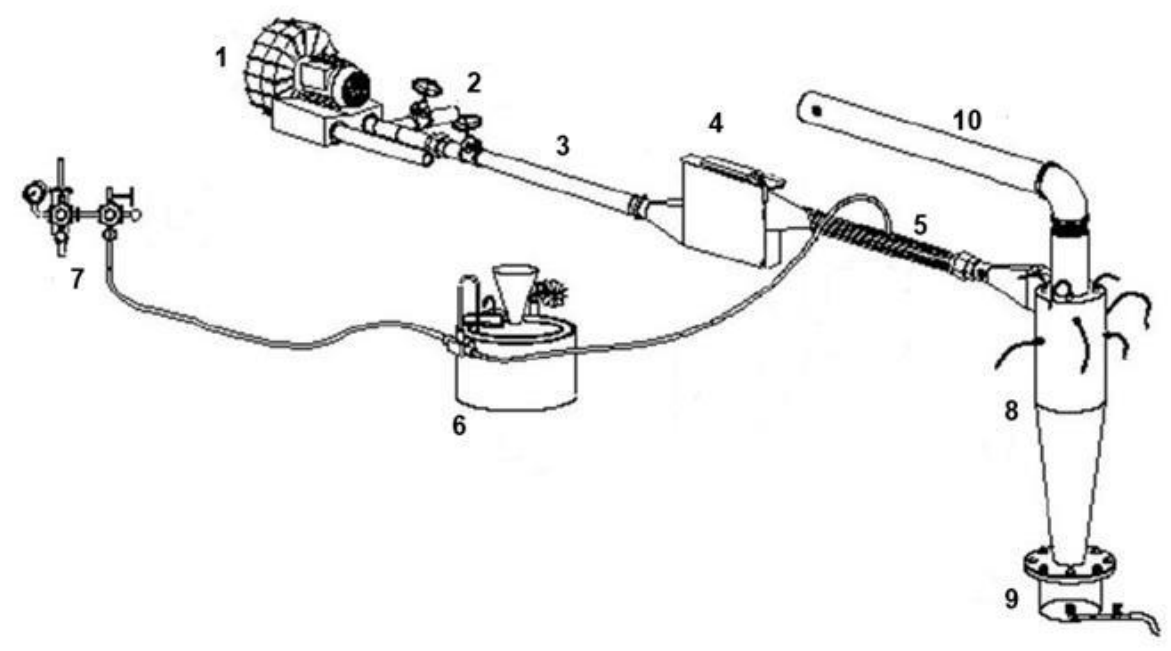

\subsection{Condições operacionais}

A velocidade do gás utilizada nos testes foi de $30 \mathrm{~m} / \mathrm{s}$ na tubulação de entrada, com temperatura ambiente, e o fluxo gasoso era gerado por um soprador.

O material particulado utilizado foi a fuligem com diâmetro médio de $9 \mu \mathrm{m}$, depositado sobre um prato giratório, e era injetado no sistema por meio de diferença de pressão. A rotação nominal do prato utilizada foi de $30 \%$, representando uma vazão mássica entrando de aproximadamente $0,5 \mathrm{~g} / \mathrm{min}$. 
Inicialmente foi realizado um teste sem a injeção de líquido a fim de avaliar a influência da injeção de líquido no equipamento, posteriormente deu-se início aos testes com injeção de água. A vazão de água era controlada por um rotâmetro, conectado à oito dutos com válvulas e bicos pulverizados, por onde a água passava para entrar no ciclone. Três vazões de água foram definidas para cada uma das três configurações dos bicos injetores, 4 superiores, 4 inferiores e 8 bicos. Na Tabela 1 são apresentadas as condições dos ensaios realizados.

Tabela 1 - Configurações testadas com o equipamento operando com injeção de líquido.

\begin{tabular}{|c|c|c|}
\hline Teste úmido & $\begin{array}{c}\text { Configuração } \\
\text { dos bicos } \\
\text { injetores }\end{array}$ & $\begin{array}{c}\text { Vazão de água } \\
(\mathrm{L} / \mathrm{h})\end{array}$ \\
\hline \hline 1 & 4 superiores & 140 \\
\hline 2 & 4 superiores & 260 \\
\hline 3 & 4 superiores & 360 \\
\hline 4 & 4 laterais & 140 \\
\hline 5 & 4 laterais & 260 \\
\hline 6 & 4 laterais & 360 \\
\hline 7 & 8 & 140 \\
\hline 8 & 8 & 280 \\
\hline 9 & 8 & 420 \\
\hline
\end{tabular}

A fim de quantificar a eficiência, foi utilizada a amostragem isocinética para coleta de amostras representativas tanto da tubulação de entrada quanto da de saída, com um tempo de coleta de 60 minutos. Foram utilizadas membranas de éster, com poro de 0,8 $\mu \mathrm{m}$ e diâmetro de $47 \mathrm{~mm}$, pesadas antes dos experimentos $\left(\mathrm{m}_{0}\right)$ e após $(\mathrm{m})$, a fim de quantificar a massa de particulado coletado $\left(\mathrm{m}_{\mathrm{c}}\right)$, expressa pela Equação 1.

$$
\mathrm{m}_{\mathrm{c}}=\mathrm{m}_{0}-\mathrm{m}
$$

Após determinar $m_{c}$, determinou-se as concentrações de partículas na entrada $\left(\mathrm{C}_{\mathrm{e}}\right)$ e na saída do ciclone $\left(\mathrm{C}_{\mathrm{s}}\right)$ pela Equação 2 e Equação 3:

$$
\begin{aligned}
& \mathrm{C}_{\mathrm{a}}=\frac{\mathrm{m}_{\mathrm{ces}}}{\mathrm{t} \cdot \mathrm{Q}_{\mathrm{S}}} \\
& \mathrm{C}_{\mathrm{s}}=\frac{\mathrm{m}_{\mathrm{css}}}{\mathrm{t} \cdot \mathrm{Q}_{\mathrm{S}}}
\end{aligned}
$$

Onde $\mathrm{m}_{\mathrm{ce}}$ é a massa de partículas coletadas na entrada, $\mathrm{m}_{\mathrm{cs}}$ é a massa de partículas coletadas na saída, t é o tempo de coleta e $\mathrm{Q}_{\mathrm{s}}$ a vazão de sucção da sonda de amostragem.

A partir da concentrações, a eficiência (n) é dada pela Equação 4:

$$
\eta=\frac{\mathrm{C}_{\mathrm{e}}-\mathrm{C}_{\mathrm{s}}}{\mathrm{C}_{\mathrm{e}}} .100 \%
$$




\section{RESULTADOS E DISCUSSÃO}

Na Figura 4 são apresentados os comportamentos da eficiência de coleta (\%) de acordo com a vazão de água para cada uma das três configurações dos bicos de injeção, além da eficiência obtida sem a injeção de líquido.

Figura 4 - Eficiência de coleta em função da vazão de água injetada para cada configuração de bicos injetores

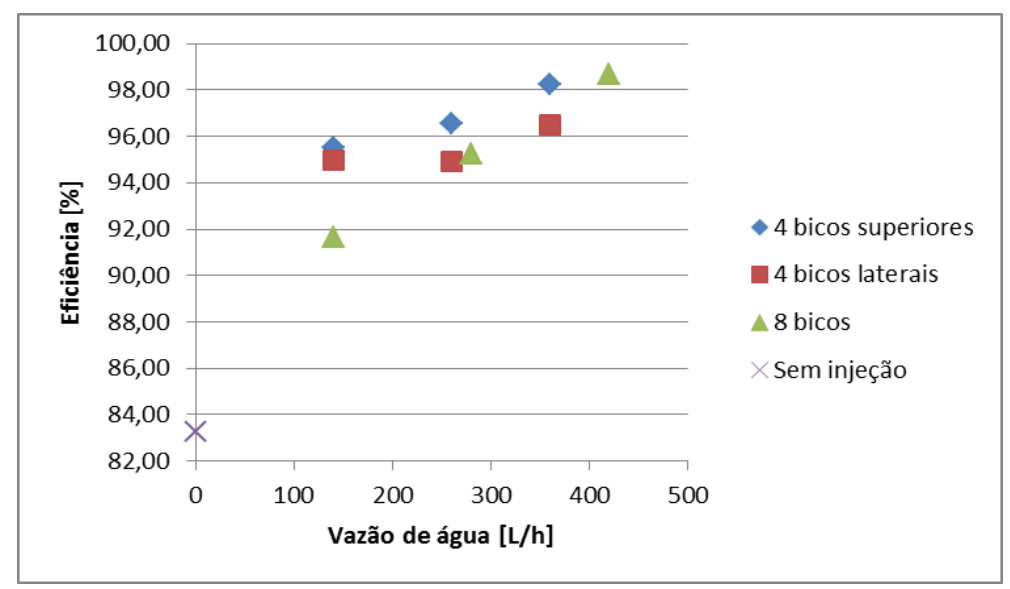

A partir da Figura 4 é possível observar um aumento de até $15 \%$ da eficiência de coleta de fuligem com a injeção de líquido. Além disso, há o aumento da eficiência com o aumento da vazão de água, visto que, uma quantidade maior de gotas de água entram em contato com as partículas a serem carregadas.

$\mathrm{Na}$ Figura 5 são comparados os comportamentos da eficiência para as duas configurações em que apenas 4 bicos de injeção de líquido foram utilizados.

Figura 5 -Eficiência de coleta em função da vazão de água injetada para as configurações com apenas 4 bicos injetores

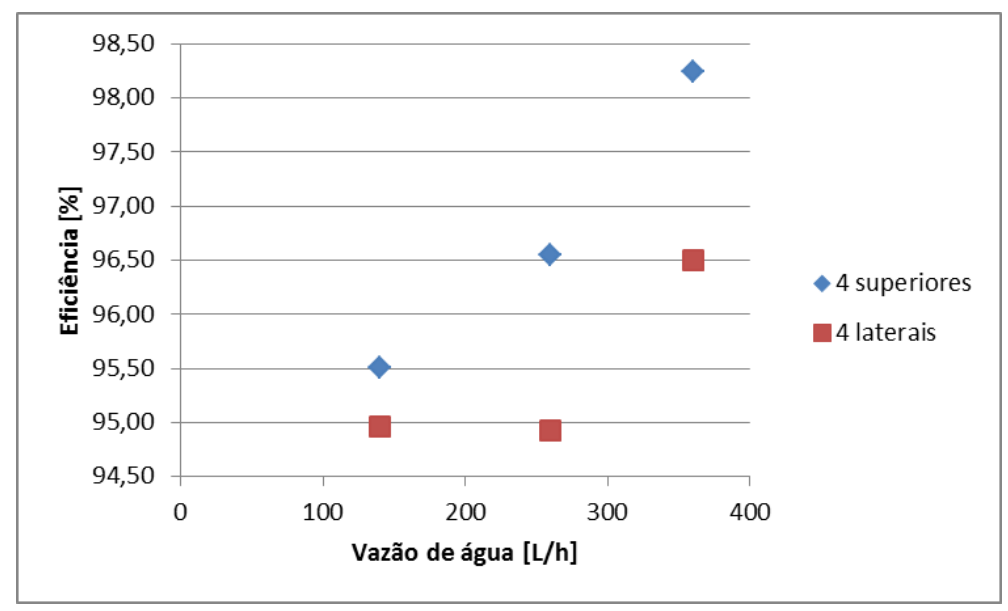


Pela Figura 5 é possível observar uma influência maior na eficiência quando os bicos injetores são superiores, indicando uma melhor otimização das mesmas vazões de água quando comparado à configuração com 4 bicos laterais.

\section{CONCLUSÃO}

A maior eficiência do equipamento operando com injeção de líquido foi de $98,7 \%$, e o aumento da eficiência do equipamento pode ser associada ao aumento da vazão de líquido injetado. As eficiências obtidas para o equipamento operando com injeção de líquido podem ser consideradas altas quando comparadas a outros equipamentos de limpeza de gás mais complexos, tornando-o uma boa alternativa de uso.

\section{REFERÊNCIAS BIBLIOGRÁFICAS}

CHIABAI JÚNIOR, J. Avaliação do Desempenho de um Ciclone Stairmand Adaptado com Bicos Injetores de Água. Dissertação de Mestrado, Universidade Federal de São Carlos, Departamento de Engenharia Química, São Carlos - SP, 2014.

LORA, E. E. S. Prevenção e controle da poluição nos setores energéticos, industrial e de transporte. 2a ed, Rio de Janeiro, Ed. Interciência, 2002, $481 \mathrm{f}$.

MAJEWSKI, R. Projeto, Construção e Avaliação Experimental de um Lavador de Gases Industriais. Tese de doutorado, Escola Politécnica da Universidade de São Paulo, São Paulo, 2006.

\section{AGRADECIMENTOS}

Os autores agradecem ao CNPQ - Conselho Nacional de Desenvolvimento Científico e Tecnológico pelo auxílio financeiro. 